Supplement of

\title{
Land-sea temperature contrasts at the Last Interglacial and their impact on the hydrological cycle
}

Nicholas King-Hei Yeung et al.

Correspondence to: Nicholas King-Hei Yeung (nicholas.yeung@unsw.edu.au)

The copyright of individual parts of the supplement might differ from the article licence. 

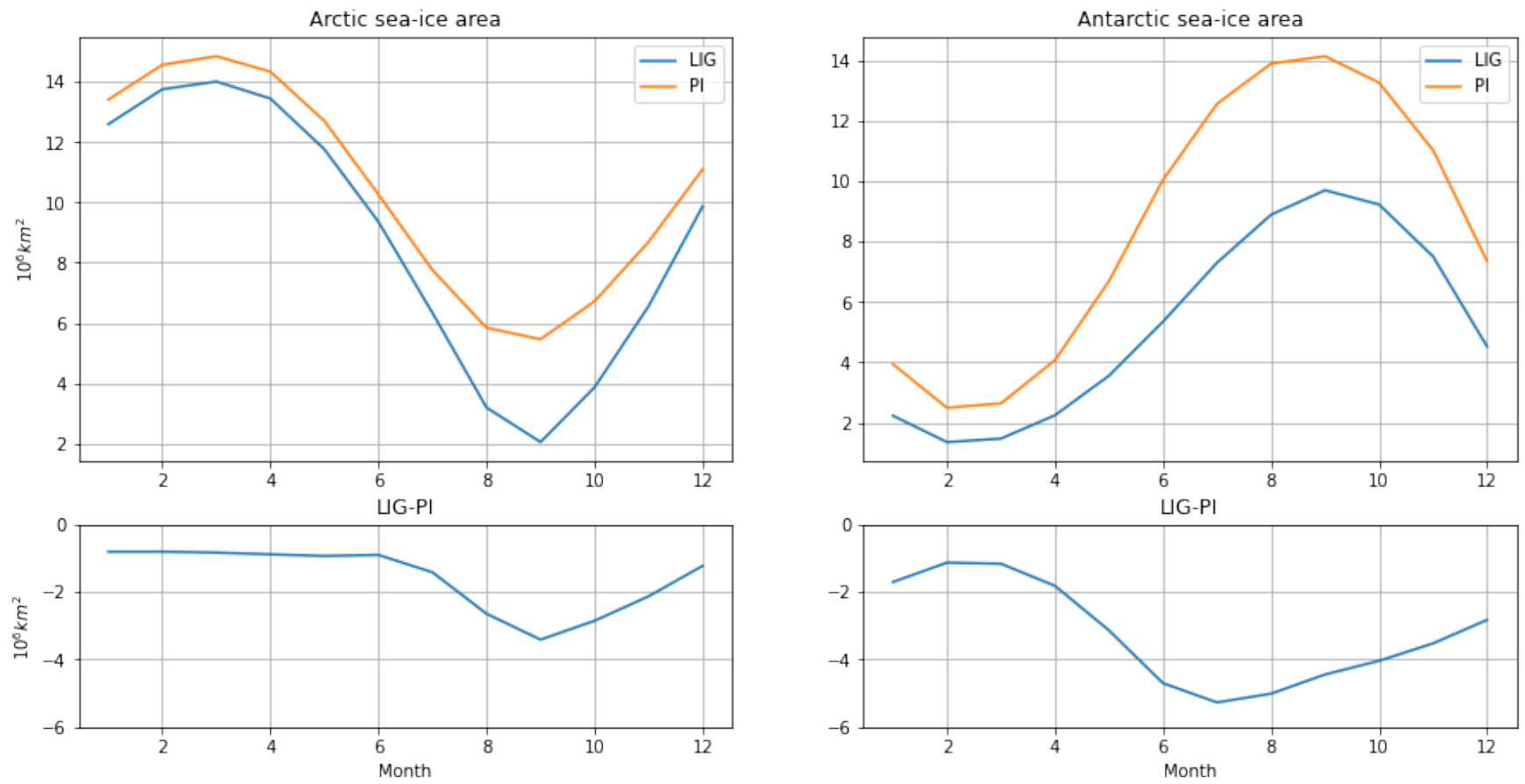

Figure S1. Simulated annual sea-ice area cycle. It is the product of sea-ice concentration and individual grid-cell area, summed over the corresponding hemisphere. 

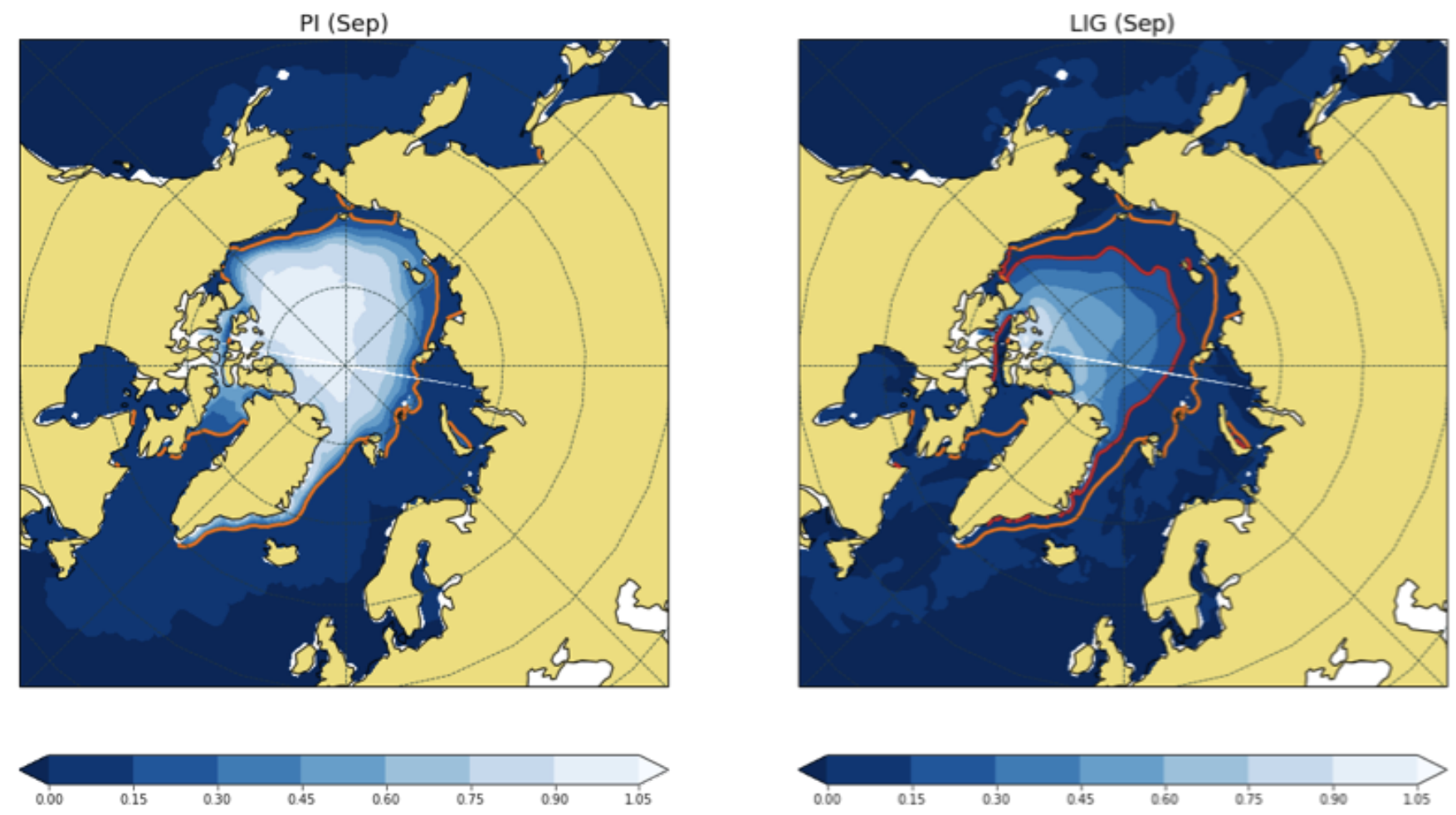

Figure S2. Arctic minimum (September, see Fig. S1) sea-ice concentration with contours at $15 \%$. LIG: red contour; PI: orange contour. 

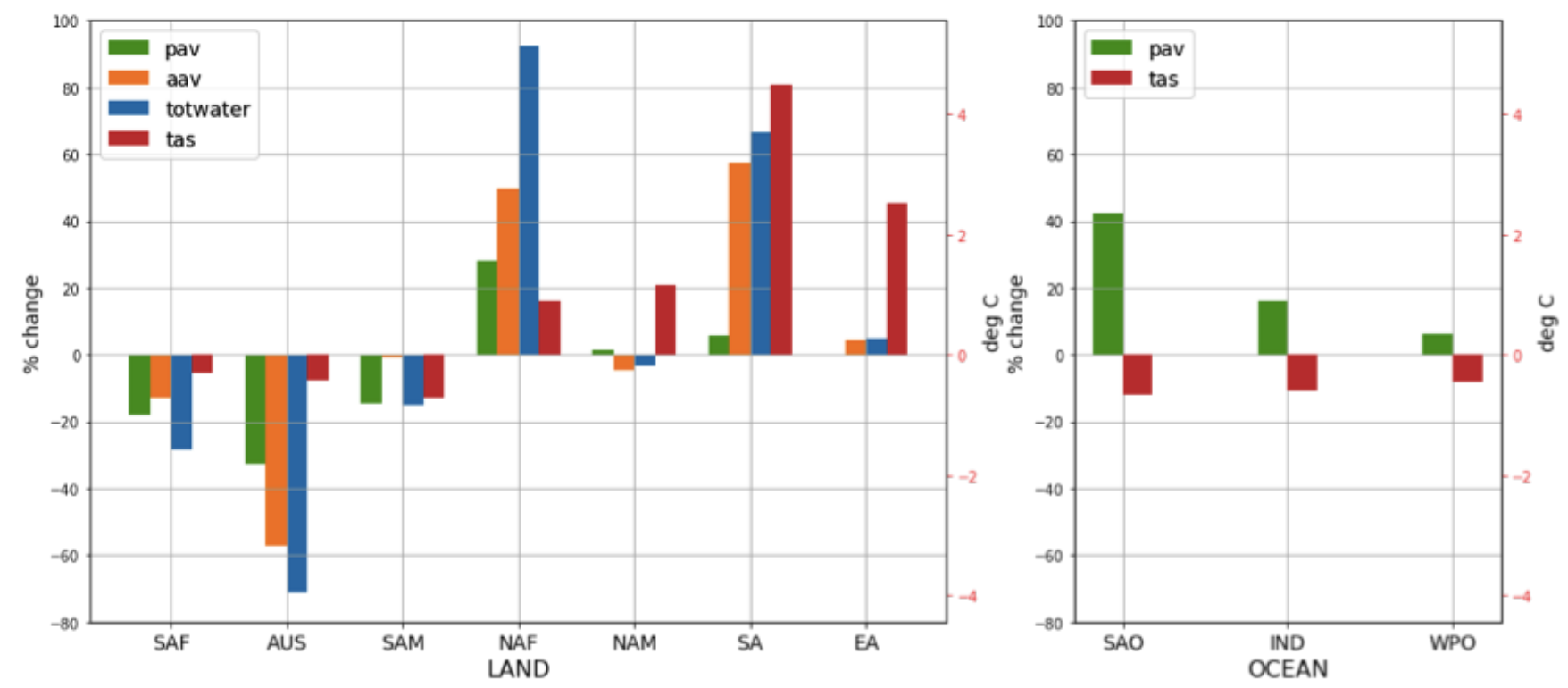

Figure S3. Changes in monsoon season (NH: MJJAS, SH: NDJFM) precipitation averaged within (left) terrestrial monsoon domains shown in Fig. 6 and (right) over SH ocean regions. This is figure is similar to Fig. 7 in the main text, but with non-calendar adjusted data. Areas in which individual monsoon and ocean regions are bounded are defined in Table S1. Pav: Percentage change in area-averaged precipitation rate during monsoon season. Aav: Percentage change in areal extent of regional monsoon domain. Totwater: Percentage change in total precipitated water during monsoon season (mean precipitation rate over monsoon domain multiplied by areal extent). TAS: air surface temperature (in ${ }^{\circ} \mathrm{C}$ ). Key: SAF = South African monsoon; AUS = Australian monsoon; SAM = South American monsoon; NAF: North African monsoon; NAM = North American monsoon; SA = South Asian monsoon; EA = East Asian monsoon; SAO = South Atlantic Ocean; IND = Southern Indian Ocean; WPO = Western to Central Equatorial Pacific Ocean. 

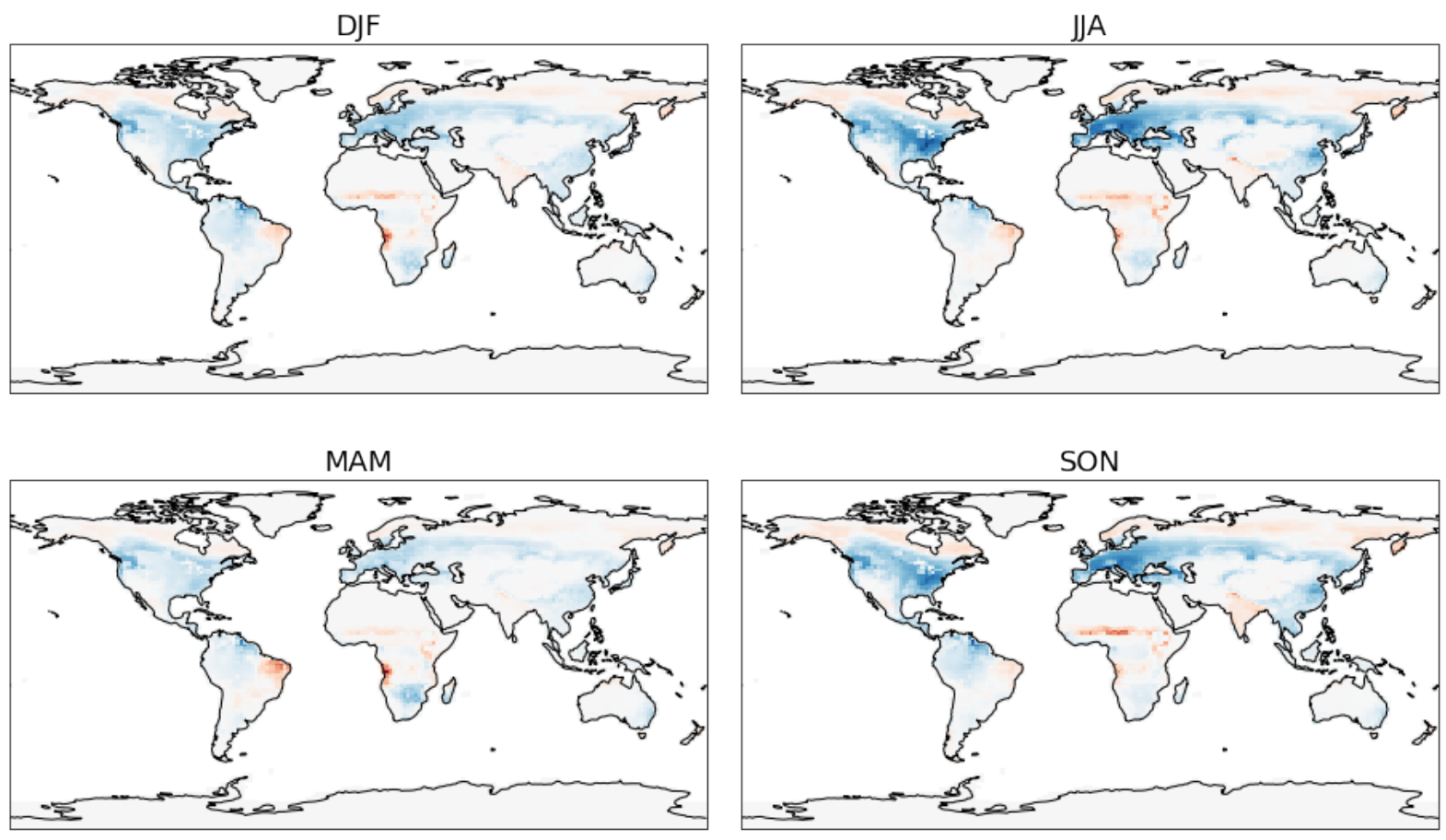

Figure S4. Simulated Leaf area index (LAI) seasonal anomaly (LIG minus PI). 
Table S1. Boundaries of monsoon regions (Wang et al., 2011) and SH ocean regions, within which changes are calculated in Fig. 7.

\begin{tabular}{ll}
\hline Monsoon regions (terrestrial) & Boundaries \\
\hline North American monsoon (NAM) & $150^{\circ} \mathrm{W}-50^{\circ} \mathrm{W}, 0-45^{\circ} \mathrm{N}$ \\
North African monsoon (NAF) & $50^{\circ} \mathrm{W}-60^{\circ} \mathrm{E}, 0-45^{\circ} \mathrm{N}$ \\
South Asian monsoon (SA) & $60^{\circ} \mathrm{E}-105^{\circ} \mathrm{E}, 0-45^{\circ} \mathrm{N}$ \\
East Asian monsoon (EA) & $105^{\circ} \mathrm{E}-180^{\circ} \mathrm{E}, 0-45^{\circ} \mathrm{N}$ \\
South American monsoon (SAM) & $120^{\circ} \mathrm{W}-30^{\circ} \mathrm{W}, 0-45^{\circ} \mathrm{N}$ \\
South African monsoon (SAF) & $0-90^{\circ} \mathrm{E}, 0-45^{\circ} \mathrm{S}$ \\
Australian monsoon (AUS) & $90^{\circ} \mathrm{E}-160^{\circ} \mathrm{E}, 0-45^{\circ} \mathrm{S}$ \\
\hline Ocean regions & \\
\hline South Atlantic Ocean (SAO) & $50^{\circ} \mathrm{W}-20^{\circ} \mathrm{E}, 0-30^{\circ} \mathrm{S}$ \\
Indian Ocean (IND) & $40^{\circ} \mathrm{E}-120^{\circ} \mathrm{E}, 0-30^{\circ} \mathrm{S}$ \\
Western to Central Equatorial Pacific Ocean (WPO) & $150^{\circ} \mathrm{E}-140^{\circ} \mathrm{W}, 0-30^{\circ} \mathrm{S}$ \\
\hline
\end{tabular}

